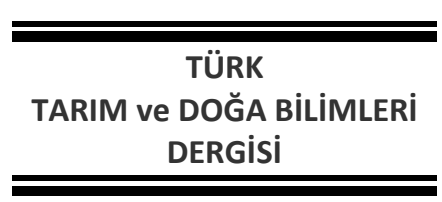

\section{Bireylerin Organik Sebze-Meyve Tüketimini Etkileyen Faktörlerin Belirlenmesi (Tokat ili Merkezi Örneği)}

TURKISH

JOURNAL Of AGRICULTURAL

and NATURAL SCIENCES

www.dergipark.gov.tr/turkjans

\author{
Rüveyda YüZBAŞıĞLU* \\ Gaziosmanpaşa Üniversitesi, Ziraat Fakültesi, Tarım Ekonomisi Bölümü, Tokat-TÜRKiYE \\ *Sorumlu yazar: ruveyda.kiziloglu@gop.edu.tr
}

Geliş Tarihi: 05.04.2018

Düzeltme Geliş Tarihi: 13.08.2018

Kabul Tarihi: 13.08.2018

\title{
Özet
}

Sebze meyve üretimin de ön plana çıkan Tokat ili, organik olarak üretilen meyve-sebze üretiminde de önemli bir yere sahiptir. Üretimin fazla olan ildeki bireylerin meyve-sebze tüketim miktarı, tercihi, alışkanlıklarını, organik üretimi bilme durumu ve organik meyve-sebze tüketimini etkileyen bazı özellikleri belirlemek bu araştırmanın amacını oluşturmaktadır. Araştırma kapsamın görüşülen 383 bireylerin ortalama yaşı 36.15, \%51.96'sı bayan, \%81.20'si evli ve 1,727.65 TL/ay geliri olduğu belirlenmiştir. Araştırmanın sonucu olarak bireylerin \%44.13'ü organik meyve sebze tükettiği belirlenmiştir. Organik meyve-sebze tüketimini etkileyen sosyo-ekonomik faktörler Binarry Logit modeli kullanılarak analiz edilmiştir. Analiz sonucunda yaş, eğitim durumları, gelir, geleneksel ürün ile organik ürünün farkını bilme, organik ürünleri hijyenik ve kaliteli bulma, bireylerin eşinin çalışması, fazla ödemeye razı olma durumları ve bireylerin çalışma durumu ile tüketme arasında pozitif bir ilişki olduğu gözlenirken cinsiyet arasında negatif bir ilişki olduğu belirlenmiştir. Bireylerin eğitim durumları ve gelirleri artması sonucu organik meyve sebzeye olan eğilim artması olasılıklı. Buda organik meyve tüketiminde gelir ile doğru orantılı bir ilişki olduğunu bir kez daha ortaya koymuştur. Bireylerin organik ürün tercih etmede pahalı olması pek anlam teşkil etmediği bunun yerine, organik meyve sebzeyi tercih etme de hijyen ve kalitenin etkisi araştırma sonucunda istatistiki olarak bir ilişki olduğu ortaya konulmuştur.

Anahtar kelimeler: Tüketim, tercih, organik meyve-sebze, binary logit.

\section{Determining of the Factors Affecting Organic Vegetables Fruit Consumption of Individuals (The Case of Tokat Province Central Example)}

\begin{abstract}
Tokat province, which is also the forefront of vegetable fruit production, also has an important place in the fruit and vegetable production which is produced organically. The aim of this research is to determine the characteristics of fruit and vegetable consumption, preference, habits, knowledge of organic production and organic fruit-vegetable consumption. The study was also interviewed by 383 individuals. The average age of the individuals was $36.15,51.96 \%$ were married, $81.20 \%$ were married and 1,727.65 TL / month were income. As a result of the research, $44.13 \%$ of the individuals consumed organic fruits and vegetables. Socio-economic factors affecting organic fruit-vegetable consumption were analyzed using the Binarry Logit model. As a result of the analysis, it was observed that there was a positive relationship between age, educational status, income, knowing the difference between traditional product and organic product, finding organic products hygienic and quality, working with individual partners, agreeing to overpay, it was determined that there was a negative relationship between gender. Individuals are likely to have an increased tendency towards organic fruits and vegetables as their educational status and income increase. It is once again revealed that there is a direct correlation with income in organic fruit consumption. It has been shown that preference for organic fruits and vegetables is statistically related to the result of hygiene and quality of research, rather than the fact that individuals prefer expensive organic products.
\end{abstract}

Key words: Consumption, preference, organic fruit-vegetable, binary logit. 


\section{Giriş}

İnsanın temel intiyaçlarından birisi olan beslenme, insan sağlığını etkileyen en önemli etmenlerin başında gelmektedir. Ancak beslenme, sadece karın doyurmak değil; vücudun ihtiyacı olan besin gruplarını yeterli ve dengeli olarak vücuda alınmasıdır. Sağlıklı olabilmek ve doğru beslenmeyi sağlamak için her gün çeşitli besinlerden yeteri kadar alınması gerekmektedir. Besinler görünüş, şekil, lezzet ve besleyici değerleri yönünden tahıl ve tahıl ürünleri, sebze ve meyveler, süt ve süt ürünleri, et, yumurta, kuru baklagiller ve yağlı tohumlar, yağlar ve şekerler olmak üzere gruplandırılmaktadır (Onur ve ark., 2017). Beslenmede öne çıkan meyvesebze grupları organik olarak tüketilmesi sağlıklı ve dengeli beslenmede daha önemli bir yer almaktadır.

Organik tarım doğadaki dengeyi koruyan, toprak verimliliğinde devamlılığı sağlayan, hastalık ve zararlıları kontrol altına alarak doğadaki canlıların sürekliliğini koruyan, doğal kaynakların ve enerjinin kullanımı ile optimum verimlilik alınan bir sistemdir (Atasay, 2006; Sandallığlu, 2014). Bu bağlamda hem çevreyi koruma hem de daha sağlıklı ve dengeli beslenme için organik meyve sebzenin tüketilmesi bir kez daha ortaya konulmaktadır.

Türkiye'de 2016 yılı itibariyle 11524.189 ton meyve ve 7900.454 ton sebze üretilmektedir. TR83 Bölgesi (Samsun, Amasya, Çorum ve Tokat) Türkiye'nin meyve üretiminin \%44.33'nü (5108.876 ton) yaparken sebze üretiminin \%94.11'li (743.544 ton) gibi büyük bir oranını yapmaktadır. Tokat ili ise Türkiye'nin meyve üretiminin \%21.64'nü, TR83 bölgesinin yarıya yakınının (\%48.82) üretirken, sebze üretiminde Türkiye'nin \%74.99'nu, bölgenin ise \%70.58'ni yapmaktadır. Sebze meyve üretimin de ön plana çıkan Tokat ili, organik olarak üretilen meyve-sebze üretiminde de önemli bir yere sahiptir. TÜiK 2016 verilerine göre Türkiye'de organik bitkisel alanı toplamda 523.777 hektar iken organik bitkisel üretim miktarı 2473.600 tondur. TR83 Bölgesi (Samsun, Amasya, Çorum ve Tokat) Türkiye'nin organik bitkisel üretim alanın \%1.76 (9.237 he) sahip iken organik bitkisel üretiminin \%1.44'nü (35.695 ton) üretmektedir. Tokat ili ise bölgenin organik bitkisel üretiminin \%42.18'lik (3.896 he) alanına sahip olup, üretimin ise $\% 54.74$ 'nü (19.540 ton) gerçekleştirmektedir.

Meyve-sebze üretimin fazla olan ildeki bireylerin meyve-sebze tüketim miktarı, tercihi, alışkanlıklarını, organik üretimi bilme durumu ve organik meyve-sebze tüketimini etkileyen bazı özellikleri belirlemek bu araştırmanın amacını oluşturmaktadır.

\section{Materyal ve Yöntem Materyal}

Bu araştırmanın materyalini, Tokat ili merkez ilçe kentsel alanda bulunan bireylerden anket yoluyla elde edilen veriler oluşturmuştur.

\section{Yöntem \\ Verilerin toplanması aşamasında izlenen yöntem}

Ana kitlenin en iyi düzeyde temsil edilecek örnek sayısının belirlenmesinde oransal örneklemden yararlanılmıştır (Yamane, 2001).

$$
\begin{aligned}
& \mathrm{n}=\frac{N p(1-p)}{(N-1) \sigma_{p}^{2}+p(1-p)} \\
& \mathrm{n}=\text { örnek büyüklüğü, } \\
& \mathrm{N}=\text { populasyon büyüklüğü (358.872), } \\
& \mathrm{p}=\text { tahmin oranı (0.5 maksimum örnek }
\end{aligned}
$$
büyüklüğü için),

$$
\sigma_{p}^{2}=\text { oran varyansı (maksimum örnek }
$$

hacmine ulaşmak için \%95 güven aralığında Çizelge değeri 1.96 ve \%5 hata payı ile). Ana kitleyi oluşturan bireylerin özellikleri başlangıçta bilinmediği için, örnek hacmini maksimum kılacak şekilde $p=0.5$ olarak alınmış ve örnek hacmi 383 birey olarak bulunmuştur. Görüşülecek bireylerin sayısının belirlenmesinde, yerleşim birimlerinin toplam popülasyon içindeki payları esas alınmış ve örneğe alınan bireyler tesadüfi olarak belirlenmiştir.

\section{Verilerin analizi aşamasında izlenen yöntem}

Organik meyve-sebze tüketimini etkileyen sosyo-ekonomik faktörler Binarry Logit modeli kullanılarak analiz edilmiştir. Logit modelinde bağımlı değişken Dummy ve tahmin edilen olasılık değerleri 0 ile 1 arasında değişmektedir.

Lojistik fonksiyon (LOGIT) genel fonksiyonel formülü (Gujarati, 1992);

$$
F_{i}\left(\beta X_{i}\right)=\frac{\exp \left(\beta X_{i}+\varepsilon_{i}\right)}{1+\exp \left(\beta X_{i}+\varepsilon_{i}\right)}
$$

$\mathrm{F}\left(\beta \mathrm{X}_{\mathrm{i}}\right)=$ Index fonksiyonunu (I nci bireyler için gözlenen organik meyve-sebze tüketimi, tüketmeyenler için $\mathrm{j}=0$; tüketenler için $\mathrm{j}=1$ ) vektörünü,

$$
\beta=\text { Açıklayıcı değişkenlerin katsayı }
$$

$\mathrm{X}_{\mathrm{i}}=$ Bireylerin karakterlerini temsil eden açıklayıcı değişkenleri,

$\varepsilon_{\mathrm{i}}=$ Hata terimini göstermektedir.

Bireylerin organik meyve-sebze tüketime olasılığı:

$$
\begin{aligned}
& \mathrm{P}_{\mathrm{i}}=\frac{1}{\left.1+e^{-z_{i}}\right]} \\
& \mathrm{P}_{\mathrm{i}}=\text { Bağımlı değişkenin olma olasıı̆̆ı } \\
& e=\text { doğal logaritmadır. }
\end{aligned}
$$




$$
Z_{i}=\beta X_{i} Z_{i} \quad Z_{i}=\beta_{1}+\beta_{2} X_{2}
$$

organik meyve-sebze tüketmeme olasılığı ise $\left(1-\mathrm{P}_{\mathrm{i}}\right)$ formülü;

$$
\frac{P_{i}}{1-P_{i}}=\frac{1+e^{+z_{i}}}{\left[1+e^{-z_{i}}\right]}=e^{z_{i}}
$$

organik meyve-sebze tüketme bahis oranı olan formülün doğal logaritması alınırsa aşağıdaki sonuca ulaşılır.

$$
\mathrm{L}_{i}=\ln \frac{P_{i}}{1-P_{i}} Z_{i}=\beta_{1}+\beta_{2} X_{2}
$$

Bahis oranının logaritması L, yalnız X'e göre değil, ana kitle katsayılarına göre de doğrusaldır. L'ye logit denir ve logit modeli formülden gelmektedir (Gujarati, 1992).

Açıklayıcı değişkenler, gözlemlenen değişkenlerden çıkartılmaktadırlar ve onların doğrusal bileşenleri olarak tahmin edilebilirler. J'inci faktör olan $\mathrm{F}_{j}^{\prime}$ in genel tahmin eşitliği şu şekilde ifade edilebilir:

$$
F_{j}=\sum_{i=1}^{p}\left[W_{j i} X_{1}+W_{j} X_{2}+\ldots+W_{j p} X_{p}\right]
$$

$\mathrm{W}_{\mathrm{i}}$ : Açıklayıcı değişkenler skor katsayılarını,

P: değişken sayısını göstermektedir.

Lojistik katsayılarını anlamak için, bir olayı olasılık oranı bakımından düşünmek gerekir (Akgül ve Çevik, 2005). Olasılık oranının doğal logaritması alınarak elde edilen lojistik regresyon modelinin parametrelerini tahmin ederken en yüksek olabilirlik (maximum likelihood) yöntemi yaygın olarak kullanılır (Berenson ve Levine, 1996).

Lojistik modelde yer alan bazı değişkenler, kategoriler arası farklııkları olasılık oranları olarak elde edilebilmek üzere kategorik değişkene çevrilmiştir. Yorumlamada kolaylık sağlaması açısından bağımsız değişkenlerin bazıları dummy değişken olarak modele alınmıştır.

Modele açıklayıcı değişken olarak; bireylerin cinsiyeti (bayan ise 0 , erkek ise 1 olarak kodlanmıştır), yaşı (sürekli değişken), eğitim durumu(lise ve lise altı ise 0 , lise üstü ise 1 olarak kodlanmıştır), medeni durum (bekar ise 0 , evli ise 1 olarak kodlanmıştır), hanede yaşayan fert sayısı (sürekli değişken), kendinin çalışma durumu (çalışmıyorsa 0 ile çalışıyorsa 1 ile kodlanmıştır), eşinin çalışma durumu (çalışmıyorsa 0 ile çalışıyorsa 1 ile kodlanmıştır), bireylerin aylık gelirleri (sürekli değişken), organik üretimden haberdar olma durumu (haberdar ise 1 , değilse 0 olarak kodlanmıştır), organik ürün ile geleneksek ürünün arasındaki farkı bilme durumu (biliyor ise 1 , bilmiyorsa 0 olarak kodlanmıştır), bireylerin, lezzet, hijyen, pahalı, kalite ve sağlıklı olduğu için organik meyve-sebzeyi tüketmeyi tercih etme durumu (tercih ediyor ise 1 , etmiyorsa 0 olarak kodlanmıştır) ve daha sağlıklı ve daha güvenilir olduğu için organik meyve-sebzeye daha fazla ödeyerek satın almaya razı olma durumu (razı ise 1 , değil ise 0 olarak kodlanmıştır) dahil edilmiştir.

\section{Bulgular ve Tartışma \\ Bireylerin genel özellikleri}

Araştırma kapsamında görüşülen bireylerin \%51.96'sı kadın iken \%44.13'ü erkek olduğu Çizelge $1^{\prime}$ den anlaşılmaktadır. Bireylerin ortalama yaşı 36.15 iken yarısından fazlasının (\%57.44) lise ve lise altı mezunu olduğu belirlenmiştir. Bireylerin \%81.20'si evli iken \%54.57'sinin çocuk sahibi olduğu ve hanelerinde ortalama olarak 4 birey yaşadığı Çizelge 1'den anlaşılmaktadır. Bireylerin ve eşlerinin çalışma durumu incelendiğinde, bireylerin \%67.62'si çalıştığı ve \%36.55'nin eşlerinin çalıştığı gözlenmiştir. Bireylerin aylık ortalama gelirleri 1.727.65 TL olduğu hesaplanmıştır.

\section{Bireylerin organik meyve sebze tüketme ve tercih durumları}

Araştırma kapsamında görüşülen bireylerin \%78.85'i ambalajsız satılan taze meyve-sebze için ve üzerinde hormonsuz, ilaçsız doğal ya da köy tipi yazan ürünlerin organik ürün olduğunu düşünmektedir. Bunun ile birlikte bireylerin yarısından fazlasının (\%66.32) organik ürün ile geleneksel ürünün arasındaki farkı bilmediği araştırma sonucunda belirlenmiştir. Ancak bireylerin \%86.68'i herhangi bir şekilde organik tarımdan haberdar olduğunu belirtmişlerdir. Yani bireyler gerek görsel gerek yazılı basından organik tarımla ilgili konular hakkında bir şeyler duymuştur. Fakat tam konuya hakim olmadıkları gerek tanımları bilmeyişleri gerek geleneksel ile organik üretimi karıştırmalarından dolayı söylenebilir.

Bireylerin yarısından fazlasının (\%55.87) organik meyve-sebzeyi tüketmezken \%44.13'ü organik meyve-sebzeyi düzenli olarak tükettiği belirlenmiştir. Sarıkaya, (2007) yılında organik ürünler üzerine yaptığı çalışmasında bireylerin \%61.2'sinin organik meyve sebze tükettiğini belirlemiştir. İnci ve ark., (2014) yılında Bingöl ili kentsel alanda yaşayan bireylerin \%84.2'si organik ürün tüketirken, organik üründen de en fazla tüketilen grubun $\% 60.6^{\prime}$ lık gibi büyük yüzde ile organik meyve sebze olduğu gözlenmiştir. İnci ve ark., (2017) yılında Diyarbakır ilindeki bireylerin \%54.5'nin organik ürün tüketirken, organik ürün grupları içerisinde de en fazla tüketilen grubun (\%45.5) organik meyve sebze olduğunu çalışması sonucu ortaya koymuştur.

Bireylerin organik meyve-sebze tüketmeyi tercih etme nedenleri incelendiğinde en önemli sebep olarak ve bireylerin yarısından fazlasının (\%53.26) lezzetli buldukları için tüketmeyi tercih ettikleri Çizelge 2'den anlaşılmaktadır. Çizelge 2 
incelendiğinde bireylerin \%34.99'u hijyenik bulduğu için, \%25.07'si pahalı bulduğu için, \%3.39'u kaliteli bulduğu için ve yalnızca \%1.83 daha sağlıklı bulduğu için organik meyve-sebze tüketmeyi tercih etmektedir. Akgüngör ve ark., (2010) yılında İstanbul ve İzmir illerinde yaptıkları çalışmalarında tüketicilerin organik ürünü seçme nedenleri arasında besin değerinin yüksek dolayısıyla daha sağlıklı olduğu sonucuna varmışlardır. Başka bir çalışmada tüketicilerin organik ürün satın alımındaki en önemli neden olarak sağlık, lezzet, tazelik ve çevre dostu olarak bulunmuştur (Ergin ve Özsaçmacı, 2011). Nitekim yurt içi ve yurt dışı çalışmaları da incelendiğinde benzer sonuçlara rastlamak mümkündür. Sarıkaya, (2007) yılında Ankara ve İstanbul illerinde yaptığı çalışmasında bireylerin organik ürün tüketme tercihlerinden en önemli ilk iki sebep incelendiğine sırasıyla şu sonuçlar elde edilmiştir; ilaç, hormon ve katkı maddesi içermediği için ve lezzetli olmasıdır. Karaman ve ark., (2013) yılında yaptıkları çalışmalarında organik ürün tüketme nedenleri incelendiğinde bireylerin \%52.8'i sağlıklı olduğu için ve \%35.7'si sağlık artı lezzetli olduğu için tükettiği sonucuna varılmıştır.

Çizelge 1. Bireylerin genel özellikleri ve bazı tanımlayıcı istatistikler.

\begin{tabular}{|c|c|c|c|c|c|}
\hline Gruplar ve Açıklaması & & Frekans & $\%$ & Ortalama & $\begin{array}{c}\text { Standart } \\
\text { Sapma }\end{array}$ \\
\hline \multirow{2}{*}{ Cinsiyet (CINSIYET) } & Erkek:1 & 184 & 48.04 & & \multirow{2}{*}{0.500} \\
\hline & Kadın:0 & 199 & 51.96 & & \\
\hline Yaş (YAS) & & & & 36.15 & 8.100 \\
\hline \multirow{3}{*}{ Eğitim Durumu (ED) } & Lise ve lise altı Mezunu & 220 & 57.44 & & \multirow{3}{*}{0.495} \\
\hline & Olanlar:0 & $2 \angle 0$ & 31.44 & & \\
\hline & Lise üstü Mezunu Olanlar:1 & 163 & 42.56 & & \\
\hline \multirow{2}{*}{ Medeni Durum (MD) } & Evli:1 & 311 & 81.20 & & \multirow{2}{*}{0.391} \\
\hline & Bekar:0 & 72 & 18.80 & & \\
\hline Hanedeki fert sayısı (FERT) & & & & 3.46 & 1.368 \\
\hline \multirow[b]{2}{*}{ Çalışma Durumu (CALIS) } & Çalışıyor: 1 & 259 & 67.62 & & \multirow[b]{2}{*}{0.469} \\
\hline & $\begin{array}{l}\text { Çalışmıyor (Emekli, İşsiz, İş } \\
\text { arıyor, öğrenci): } 0\end{array}$ & 124 & 32.38 & & \\
\hline \multirow{2}{*}{$\begin{array}{l}\text { Eşinin Çalışma Durumu } \\
\text { (ESCALIS) }\end{array}$} & Çalışıyor: 1 & 140 & 36.55 & & \multirow[b]{2}{*}{0.482} \\
\hline & $\begin{array}{l}\text { Çalışmıyor (Emekli, İşsiz, İş } \\
\text { arıyor, öğrenci): } 0\end{array}$ & 243 & 63.45 & & \\
\hline Gelir (ay/TL) (GELIR) & & & & 1727.650 & 926.955 \\
\hline \multirow{2}{*}{$\begin{array}{l}\text { Çocuk Sahibi Olma } \\
\text { Durumu (COCUK) }\end{array}$} & Çocuk sahibi olanlar:1 & 209 & 54.57 & & \multirow{2}{*}{0.499} \\
\hline & Çocuk sahibi olmayanlar:0 & 174 & 45.43 & & \\
\hline
\end{tabular}

Bireylerin daha sağlıklı ve güvenilir ürün için daha fazla ödeyerek organik meyve-sebze satın almaya razı olma durumları incelendiğinde \%69.71'lik gibi büyük bir kısmının daha fazla ödemeye razı olmadığı Çizelge 2'den anlaşılmaktadır. Millock ve ark., (2002) yılında Danimarka'da yaptıkları çalışmalarında tüketicilerin \%35 organik tarım ve gıda ürünleri için mevcut piyasa fiyatından daha fazla ödemeye razı oldukları sunucunu bulmuşlardır. Urena ve ark., (2008) yılında İspanya da yaptıkları çalışmalarında kadın tüketicilerin erkeklere göre organik ürünleri için daha fazla ödeme istekliliği olduğu sonucuna varmışlardır.

\section{Bireylerin organik meyve-sebze tüketimini etkileyen faktörler}

Bireylerin organik meyve sebze tüketimini etkileyen faktörlerin binary logit analiz sonucu Çizelge 3'de verilmiştir. Analiz sonuçlarına göre \%1 önem seviyesinde bireylerin yaşı, eğitim durumları, gelirleri, organik ürün ile geleneksel ürünün farkını bilme, hijyenik ve kaliteli olduğu için tüketmeyi tercih etme pozitif yönlü tüketmeyi etkilerken bireylerin cinsiyeti negatif yönlü etkilediği belirlenmiştir. Benzer bir sonuca İnci ve ark., (2014) yılında Bingöl ilinde yaptıkları araştırmada rastlanmıştır. Araştırmalarında organik ürün tüketimi ile bireylerin geliri ve cinsiyeti arasında $\mathrm{Khi}^{2}$ analizi sonucunda anlamlı bir ilişki bulunmuştur. Benzer sonuçlar yurt dışı çalışmalarında da rastlanmıştır. Örneğin; Stobbelaar ve ark., (2007) yılında Hollanda'da ve Hassan ve ark., (2009) yılında Fransa'da yaptıkları çalışmalarında organik gıda satın alımında eğitim seviyesinin anlamlı bir ilişkisi olduğunu belirlemişlerdir. Başka bir çalışma ise; Chen (2007) yılında yaptığı çalışmada tropik meyve tüketimini etkileyen faktörleri sıralı çok değişkenli kesikli tercih modeli ile analiz etmiştir. Analiz sonucunda, tüketim ile eğitim durumu ve gelir 
seviyesi arasında anlamlı bir ilişki bulmuşlardır. Vukosovic, (2016) yılında yaptığı araştırmasında Anova testi sonucunda; kadınların organik meyve sebzeyi tadı ve daha sağlıklı buldukları için erkeklere oranla daha fazla tercih ettiğini ortaya koymuştur. Yurt içinde de benzer sonuçlara rastlanmıştır; Armağan ve Özdoğan, (2005) yıllarında Aydın ilinde yaptıkları çalışmalarında ise gelir ve eğitim durumu arttıkça daha sağlıklı ve lezzetli olan organik ürün tüketimi de artığını belirtmişlerdir. Bireylerin yaşındaki bir birimlik artış organik meyve-sebze tüketimini \%1 oranında artırması olasılığı söz konusudur. Eğitim durumundaki bir birimlik artış tüketimi \%15 artırmasını beklenmektedir. Bireylerin gelirindeki bir birimlik artış tercihi \%1 artırması yönünde etki yapması beklenmektedir. Organik ürün ile geleneksel ürünün fakını bilenler bilmeyenlere göre \%17 daha fazla organik meyve sebze tüketmeyi tercih etmesi beklenmektedir. Bayanların erkeklere göre \%24 olasılıkla daha fazla organik meyve sebze tüketimi söz konusudur. Organik meyve sebzeyi daha hijyenik bulanlar bulmayanlara göre \%22 olasılıkla daha fazla tercih etmekte, aynı şekilde kaliteli bulanlar bulmayanlara göre \%36 olasılıkla daha fazla tercih etmesi beklenmektedir.

Çizelge 2. Bireylerin organik meyve-sebze tercihinde dikkat ettikleri hususlar.

\begin{tabular}{llccc}
\multicolumn{1}{c}{ Gruplar ve Açıklaması } & & Frekans & \% & $\begin{array}{c}\text { Standart } \\
\text { Sapma }\end{array}$ \\
\hline Bağımlı Değişken (Y) & Tüketiyorsa:1 & 169 & 44.13 & 0.497 \\
Organik Tarımdan Haberdar Olma Durumu & Tüketmiyorsa:0 & 214 & 55.87 & \\
(HABERDAR) & Olanlar:1 & 332 & 86.68 & 0.340 \\
Organik Ürün İle Geleneksel Ürün Arasındaki Farkı & Olmayanlar:0 & 51 & 13.32 & \\
Bilme Durumu (FARK) & Bilenler:1 & 129 & 33.68 & 0.473 \\
Daha Lezzetli Olduğu İçin Organik Meyve-Sebze & Tercih Ediyorsa:1 & 254 & 66.32 & \\
Tüketmeyi Tercih Etme Durumu (LEZZET) & Tercih Etmiyorsa:0 & 179 & 53.26 & 0.499 \\
Daha Hijyenik Olduğu İçin Organik Meyve-Sebze & Tercih Ediyorsa:1 & 134 & 34.99 & 0.478 \\
Tüketmeyi Tercih Etme Durumu (HIJYEN) & Tercih Etmiyorsa:0 & 249 & 65.01 & \\
Daha Pahalı Olduğu İçin Organik Meyve-Sebze & Tercih Ediyorsa:1 & 96 & 25.07 & 0.434 \\
Tüketmeyi Tercih Etme Durumu (PAHALI) & Tercih Etmiyorsa:0 & 287 & 74.93 \\
Daha Kaliteli Olduğu İçin Organik Meyve-Sebze & Tercih Ediyorsa:1 & 13 & 3.39 & 0.181 \\
Tüketmeyi Tercih Etme Durumu (KALITE) & Tercih Etmiyorsa:0 & 370 & 96.61 & 0.13 \\
Daha Sağlıklı Olduğu İçin Organik Meyve-Sebze & Tercih Ediyorsa:1 & 7 & 1.83 \\
Tüketmeyi Tercih Etme Durumu (SAGLIK) & Tercih Etmiyorsa:0 & 376 & 98.17 & 0.134 \\
Daha Sağlıklı ve Güvenilir Ürün İçin Daha Fazla & Razı olanlar:1 & 116 & 30.29 \\
Ödemeye Razı Olma Durumu (FAZLAODE) & Razı olmayanlar:0 & 267 & 69.71 & 0.460 \\
\hline
\end{tabular}

\%5 önem seviyesinde anlamlı bulunan satın almada daha fazla ödemeye razı olma pozitif yönlü etkisi olurken eşinin çalışması negatif yönlü etkisi olduğu analiz sonucunda anlaşılmıştır. Yani daha sağlıklı ve güvenilir ürün için daha fazla ödemeye razı olanlar olmayanlara göre \%14 olasılıkla organik meyve sebze tüketmeyi tercih etmektedir. Eşleri çalışanlar çalışmayanlara göre \%15 olasılıkla daha az organik meyve sebze tüketmeyi tercih etmektedir. \%10 önem seviyesinde anlamlı bulunan bireylerin çalışması tüketmeyi pozitif etkilediği analiz sonucunda ortaya koymuştur. Bireylerin çalışmasındaki bir birimlik artış organik meyve sebze tüketmeyi tercih etmede \%11 oranında artırması olası bir sonuçtur. Benzer bir sonuca İnci ve ark., (2014) yılında Bingöl ilinde yaptıkları araştırmada rastlanmıştır. Araştırmalarında organik ürün tüketimi ile bireylerin çalışması arasında $\mathrm{khi}^{2}$ analizi sonucunda anlamlı bir ilişki bulunmuştur.

\section{Sonuç ve Öneriler}

Son zamanlarda gerek görsel gerek sosyal medyada sözü geçen organik meyve sebze tüketimi bu araştırma da incelenmeye çalışılmıştır. Meyve sebzenin üretim seviyesi yüksek olan Tokat ilinde ki bireylerin yarısına yakını organik meyve sebze tüketmediği ya da tüketmeyi tercih etmediği bu araştırma ile belirlenmiştir. Tüketimi etki eden faktörler istatistiki olarak incelendiğinde ekonomik teoride de önemli bir yeri olan gelirin etkili olduğu bu araştırma ile bir kez daha ortaya konulmuştur. Meyve sebzeye göre daha pahalı olan organik ürünlere olan talep bireylerin gelirleri arttıkça tüketme istekliliği artacağı istatistiki olarak ortaya konulmuştur. Bir önemli sonuçta bireylerin eğitim durumundaki ilerleme daha sağlıklı olan organik meyve sebze tüketimini pozitif yönde etkileyeceği ortaya konulmuştur. Bireylerin yaşlarının ilerlemesi organik meyve sebze tüketimine daha eğilimli olması analiz sonucunda beklenmektedir. 
Araştırma sonucu bireylerin fiyat faktörünün artık en önemli kriter olarak görmemektedir. Bunun yanı sıra organik ürünü sağlıklı veya hijyenik ya da kaliteli buldukları için değil lezzetinden dolayı tercih ettikleri araştırma sonucu ortaya konulmuştur. Yani bireyler meyve sebze tüketiminde lezzetten dolayı organik meyve tükettiği söylenebilir.
Yani bireylerde artık bir bilinçlenme ve satın alma gücüne göre satın aldıkları üründe kalite ve hijyen ön plana çıktığı bu araştırma ile ortaya konulmuştur. Bu sonuç doğrultusunda daha bilinçli bir üretim yapılması ve satın alma potansiyeli karşısında iyileştirilmiş tarım politikaları geliştirilebilinir.

Çizelge 3. Bireylerin organik meyve-sebze tüketimini etkileyen faktörlerin binary logit analiz sonucu.

\begin{tabular}{|c|c|c|c|c|c|}
\hline & Kat Sayı & Standart Hata & $\mathbf{z}$ & $|z|>Z^{*}$ & Marjinal Etki \\
\hline SABIT & $-6.298 * * *$ & 1.353 & -4.65 & 0.000 & \\
\hline CINSIYET & $-1.782 * * *$ & 0.428 & -4.17 & 0.000 & $-0.242 * * *$ \\
\hline YAS & $.0717^{* * *}$ & 0.024 & 2.97 & 0.003 & $0.009 * * *$ \\
\hline ED & $1.156^{* * *}$ & 0.384 & 3.01 & 0.003 & $0.148 * * *$ \\
\hline MD & -0.655 & 0.544 & -1.21 & 0.228 & -0.086 \\
\hline FERT & 0.218 & 0.134 & 1.62 & 0.104 & 0.028 \\
\hline CALISMA & $0.874^{*}$ & 0.477 & 1.83 & 0.067 & $0.112^{*}$ \\
\hline ESCALISMA & $-1.28 * *$ & 0.578 & -2.22 & 0.027 & $-0.146 * *$ \\
\hline GELIR & $0.001 * * *$ & 0.000 & 3.82 & 0.001 & $0.001 * * *$ \\
\hline HABERDAR & 0.169 & 0.460 & 0.37 & 0.713 & 0.021 \\
\hline FARK & $1.169 * * *$ & 0.351 & 3.33 & 0.001 & $0.167^{* * *}$ \\
\hline LEZZET & -0.052 & 0.343 & -0.15 & 0.879 & -0.007 \\
\hline HIJYEN & $1.673 * * *$ & 0.377 & 4.44 & 0.000 & $0.222 * * *$ \\
\hline PAHALI & -0.599 & 0.435 & -1.38 & 0.168 & -0.075 \\
\hline KALITE & $2.703 * * *$ & 0.923 & 2.93 & 0.003 & $0.362 * * *$ \\
\hline SAGLIK & 1.538 & 0.973 & 1.58 & 0.114 & 0.209 \\
\hline COCUK & 0.469 & 0.321 & 1.46 & 0.144 & 0.059 \\
\hline FAZLAODE & $1.001 * *$ & 0.391 & 2.56 & 0.011 & $0.142 * *$ \\
\hline
\end{tabular}

Not: $* * *, * *, *==>$ Önem seviyesinde temsili \%1, \%5, \%10

log likelihood:-151.59, Khi kare [17d.f.]: 222.47,

Restricted log likelihood: -262.83, McFadden $\mathrm{R}^{2}$ : 0.42, Hosmer-Lemeshow Khi ${ }^{2}: 22.65$

\section{Kaynaklar}

Akgül, A., Çevik, O. 2005. İstatistiksel Analiz Teknikleri. Emek Ofset Ltd. Şti. 2. Baskı. s.y. 428. Ankara.

Akgüngör, S., Miran, B., Akbay, C. 2010. Consumer willingness to pay for organic products in urban Turkey. Journal of International Food and Agribusiness Marketing, pp. 299-313.

Armağan, G., Özdoğan, M. 2005. Ekolojik yumurta ve tavuk etinin tüketim eğilimleri ve tüketici özelliklerinin belirlenmesi. Hayvansal Üretimi, 46(2): 14-21.

Atasay, A., 2006. Bitkisel Üretimde Organik Tarım. Eğridir Bahçe Kültürleri Araştırma Enstitüsü Dergisi, Yayın No 1: 1-3, Isparta.

Berenson, M.L., Levine, D.M. 1996. Basic Business Statistics Concepts and Applications. Sixth ed. p. 837. Prentice-Hall International, New York.

Chen, M.F. 2007. Consumer attitudes and purchase intentions in relation to organic foods in Taiwan: moderating effects of food-related personality traits. Food Quality and Preference, 18: 1008-1021.
Ergin, E.A., Özsaçmacl, B. 2011. Turkish consumers' perceptions and consumption of organic foods. African Journal of Business Management, 5(3): 910-914.

Gujarati, N.D. 1992. Essential of Econometrics. Mc Graw Hill. New York. 1999. Temel Ekonometri. Çeviren: Şenesen, Ü., Şenesen. G.G. Literatür Yayıncılık, İstanbul.

Hassan, D., Monier-Dilhan, S., Nichèle, V., Simioni, M. 2009. Organic Food Consumption Patterns in France. Pre-Conference Workshop, Diet and Obesity: Role of Prices and Policies August 16.

İnci, H., Karakaya, E., Söğüt, B., Şengül, T. 2014. Organic product consumption and customer preferences in urban sections of Bingol province. Türk Tarım ve Doğa Bilimleri Dergisi 1(2): 255-261.

İnci, H., Karakaya, E., Şengül, Y.A. 2017. Organik ürün tüketimini etkileyen faktörler (Diyarbakır ili örneği). KSÜ Doğa Bilimleri Dergisi, 20(2): 137-147.

Karaman, S., Özsayın, D., Karahan, H. 2013. Organik yaş meyve ve sebzelerin doğrudan 
pazarlanmasında tüketici memnuniyeti. Tarım Bilimleri Araştırma Dergisi, 6(1): 83-87.

Millock, K., Hansen, L.G., Wier, M., Andersen, L.M. 2002. Willingness to Pay for Organic Foods: A Comparison between Survey Data and Panel Data from Denmark. http://weber.ucsd.edu/ carsonvs/papers $/ 5$ 065.pdf.

Onur, N., Sarper, F., Onur, F. 2017. Farklı sosyoekonomik düzeydeki ailelerin sebze-meyve tüketim durumları. The Journal of Tourism and Gastronomy Studies, 105-123.

Sandallığlu, A., 2014. Adana İlinde Organik Tarım Ürünleri Tüketimi ve Tüketici Eğilimleri. Çukurova Üniversitesi, Fen Bilimleri Enstitüsü, Tarım Ekonomisi Anabilim Dalı (Doktora Tezi).

Sarıkaya, N. 2007. Organik ürün tüketimini etkileyen faktörler ve tutumlar üzerine bir saha çalışması. Kocaeli Üniversitesi Sosyal Bilimler Enstitüsü Dergisi, 2(14): 110-125.

Stobbelaar, D.J., Casimir, G., Borghuis, J., Marks, I., Meijer, L., Zebeda, S. 2007. A Adolescents' attitudes toward organic food: A survey of 15 to 16 year old school children. Intentional Journal of Consumer Studies, 31(4): 349-356.

TÜik, 2016. Organik Bitkisel Üretim. (www.tuik.gov.tr) (Erişim Tarihi: 28.04.2018).

Urena, F., Bernabeu, R., Olmeda, M. 2008. Women, men and organic food: differences in their attitudes and willingness to pay. A Spanish case study. International Journal of Consumer Studies, 32(1): 18-26.

Vukosovic, T. 2016. Consumers' perceptions and behaviors regarding organic fruits and vegetables: Marketing trends for organic food in the twenty-first century. Journal of Internatıonal Food \& Agribusıness Marketıng, 28(1): 59-73.

Yamane, T. 2001. Temel Örnekleme Yöntemleri. Çevirenler: Alptekin Esin, Celal Aydın, M. Akif Bakır, Esen Gürbüzsel, Literatür Yayıncılık, İstanbul. 